\begin{abstract}
Cite as:
Holt, D. and Barkemeyer, R. (2012), Media coverage of sustainable development issues - attention cycles or punctuated equilibrium? Sustainable Development, 20(1), pp. 1-17.

\section{MEDIA COVERAGE OF SUSTAINABLE DEVELOPMENT ISSUES - ATTENTION CYCLES OR PUNCTUATED EQUILIBRIUM?}

\begin{abstract}
Over the last two decades there has been a marked change in the way that the public perceives environmental issues and the concepts associated with sustainable development. Few would argue that this has moved into the mainstream of public consciousness. Coverage of sustainability related concepts within the media, as illustrated by a sample of 112 worldwide newspapers, shows a clear upward trajectory. Taking the example of climate change and sustainable development, this paper explores this increasing coverage, and arguably awareness, of sustainability concepts, and considers parallels with the concepts of punctuated equilibrium and issue-attention cycles.
\end{abstract}

Keywords: sustainability; newspapers; punctuated equilibrium; evolution; issue-attention cycle; climate change

\title{
INTRODUCTION
}

The last two decades have seen a sea change in the prominence of environmental and social issues within the public sphere and the corporate world, often facilitated by media coverage on television, in newspapers, online, and through films and documentaries. Environmental messages and social issues are also communicated through more structured channels such as school curricula and environmental education programmes (Tilbury, 1995). The media plays a key role in the development of public discourse on issues such as the Bhopal disaster, the Enron scandal, the Mattel recall, Brent Spar, sweatshop labour, and the global issue of climate change. The media represents a 'mediated public sphere' that shapes global citizenship and may play a powerful role in enhancing a sense of global connectedness (Szerszyski et al., 2000).

Norris (2001) assigns three distinct functions to the media in a representative democracy: acting as a civic forum, a mobilizing agent, and a watchdog, playing a key role in such civil societies through monitoring behaviour and promoting behaviour changes, by directing public attention towards a specific policy concern, and by heightening public attention to issues (Givel, 2006). Ryghaug (2010) notes how the media has played a key role in setting climate change discourse and setting the agenda of how such discourse reaches the public. Communiqués within the public sphere take a number of different forms and channels, ranging through printed newspapers, televised news, and the use of internet technologies. In this study we explore the use of newspaper samples, allowing the timing of each communication to be related to events happening in the outside world. Data quality in printed media may be of a higher standard than an online source, and using printed media facilitates longitudinal analysis, as the same format is used. Using newspaper articles also allows our findings to be analysed in a quantitative manner, similar to that of Mazur and Lee (1993) and Trumbo (1996). Nelkin (1995) states that newspapers are the most important information source for dissemination of scientific knowledge, with the media mediating the exposure of expert opinion to 'local' stakeholders (Morse, 2008). 
The rise in media coverage of sustainability-related concerns and increasing levels of public awareness have not developed homogeneously over the last two decades. SustainAbility have tracked public, government, and corporate interest in sustainability issues and concepts within the printed media, and found that they move in great waves and downwaves, each creating new political, regulatory, and market conditions for business. The media are responsible for creating the conditions within which these waves emerge and then dramatize the ups and downs of these (SustainAbility, 2002). When we consider the global sustainability timeline a number of key events may form the basis of some media coverage. The list presented in Table 1 is not exhaustive and readers are directed toward sources such as sustainability timeline produced by IISD (2007). This is not a definitive timeline encompassing all potential events, but represents examples of the kinds of issues that may rise to prominence.

Table 1. Major climate change/sustainability events

\begin{tabular}{|c|c|}
\hline $\begin{array}{l}\text { Rowland and Molina release CFCs work in the scientific journal, Nature, calculating that continued } \\
\text { use of CFC gases at an unaltered rate would critically deplete the ozone layer. }\end{array}$ & 1974 \\
\hline $\begin{array}{l}\text { World Conservation Strategy released by IUCN. The section "Towards Sustainable Development" } \\
\text { identifies the main agents of habitat destruction as poverty, population pressure, social inequity, and } \\
\text { trading regimes. }\end{array}$ & 1980 \\
\hline Antarctic ozone hole discovered by British and American scientists. & 1985 \\
\hline Montreal Protocol on Substances that Deplete the Ozone Layer is adopted. & 1987 \\
\hline Brundland report released & 1987 \\
\hline Intergovernmental Panel on Climate Change established & 1988 \\
\hline Earth Summit in Rio (UNCED) & June 1992 \\
\hline $\begin{array}{l}\text { The Business Council for Sustainable Development publishes Changing Course - establishes business } \\
\text { interests in promoting SD practices. www.wbcsd.ch }\end{array}$ & 1992 \\
\hline Framework convention on climate change at Kyoto & Dec 1997 \\
\hline $\begin{array}{l}\text { Unusually severe weather. China experiences worst floods in decades; two-thirds of Bangladesh } \\
\text { underwater for several months from monsoons; Hurricane Mitch destroys parts of Central America; } \\
54 \text { countries hit by floods and } 45 \text { by drought; Earth hits highest global temperature ever recorded. }\end{array}$ & 1998 \\
\hline UN Millennium Summit and Millennium Goals & Sept 2000 \\
\hline $\begin{array}{l}\text { Miss Waldron's red Columbus monkey declared extinct. IUCN Red Book, 11,046 species are now } \\
\text { threatened with extinction. }\end{array}$ & 2000 \\
\hline World Summit on Sustainable Development in Johannesburg & Aug 2002 \\
\hline Wal-Mart speech by CEO announcing moves towards sustainability & Oct 2005 \\
\hline Hurricane Katrina and New Orleans floods & Aug 2005 \\
\hline Stern Review on economics of climate change released & Oct 2006 \\
\hline Inconvenient Truth released & May 2006 \\
\hline Al Gore and IPCC awarded Nobel Peace prize & Oct 2007 \\
\hline Live Earth concerts to raise awareness of climate change & July 2007 \\
\hline
\end{tabular}

Whilst it cannot be argued that there is always a direct linear correlation between coverage of a specifi c event, public opinion, and a change in behaviour (Lewis, 2000), there is no doubt that media coverage is related to - and can influence - the level of awareness of specific issues and public attention on environmental issues such as climate change (Hester and Gonzenbach, 1997). The role of the news media in this is explored by Mazur and Lee (1993, p. 682), who state 'the most widely accepted effect of the news media on public opinion is agenda setting - the placing of certain issues or problems foremost in the public mind'. The agenda-setting hypothesis was originally formulated 
by Cohen $(1963$, p. 13), who suggested that the printed news media 'may not be successful much of the time in telling people what to think, but [they are] stunningly successful in telling its readers what to think about'.

The volume of media coverage can generally indicate the relative salience that is awarded to an issue over time in a given context (Mueller, 1973; Benton and Frazier, 1976; Naisbitt, 1976; Beniger, 1978; Dearing and Rogers, 1996; Carvalho, 2005). Hence, measuring media salience by the volume or frequency of media coverage has emerged as a relatively common method in agenda-setting research (Funkhauser, 1973a; Benton and Frazier, 1976; Howlett, 1997), as critiqued by Kiousis (2004). Examples in the context of sustainability include the coverage of EU environmental policies (Bijsmans and Altides, 2007), climate change (Brossard et al., 2004; Boykoff, 2007), or HIV/AIDS (Dearing, 1989).

However, there is no consensus on the exact relationship between media coverage, public opinion, and public policy. A range of models have been developed that theorize this relationship (Downs, 1972; Funkhauser, 1973a, 1973b; Neuman, 1990; Gonzenbach, 1992; Baumgartner and Jones, 1991, 1993; Dearing and Rogers, 1996; Yanovitzky, 2002; Eichhorn, 2005). Two of the most influential models that have frequently been applied in the context of agenda-setting are the 'issue-attention cycle' developed by Downs (1972; Neuman, 1990; Nisbet and Huge, 2006), and the 'punctuated equilibrium model' developed by Baumgartner and Jones $(1991,1993)$. Both models are reviewed by Howlett (1997) and applied to the emergence of Canadian environmental policy.

Downs (1972) suggests a cyclical pattern of agenda setting and public policy making. In essence, public attention is attracted by the emergence of specific events or issues, and eventually triggers public policy responses. Public attention, however, soon diminishes as the complexity of policy making increases. Baumgartner and Jones apply the evolutionary concept of 'punctuated equilibria' (Eldredge and Gould, 1972; Gould and Eldredge, 1977) to the media-policy nexus and suggest that the impact of the agenda-setting process is determined by the power dynamics of policy subsystems (Baumgartner and Jones, 1991, 1993). Along these lines, increased levels of media coverage may trigger external shocks to - up to this point - relatively stable 'policy monopolies' (Baumgartner and Jones, 1993), and consequently bring about the destruction or reorganization of these policy monopolies, resulting in a new, 'punctuated', equilibrium.

The two models have very different implications and arguably only hold for issues that show certain characteristics. Taking the example of climate change and sustainable development, this paper explores this increasing coverage of sustainability concepts and considers parallels with the concepts of punctuated equilibrium, and Downs' issue-attention cycle. A number of studies have considered the quantitative rise and fall in printed media coverage of environmental issues, though most consider fairly restricted data sets with a geographical bias, typically concentrating on a small sample of national newspapers (Ungar, 1992; Mazur and Lee, 1993; Trumbo, 1996; Howlett, 1997; McComas and Shanahan, 1999; Lewis, 2000). This paper analyses the levels of coverage on climate change and sustainability within a sample of 112 leading national broadsheet newspapers in seven languages between 1990 and 2008. A keyword search of key terms related to climate change and sustainable development within the sample of print media has been carried out, covering approximately 24000 000 articles in 324000 newspaper issues. The research objectives of this paper are to

- consider the level of coverage of sustainability and climate change within our sample of 112 worldwide newspapers to describe and analyse the trends in coverage and - explore whether these trends demonstrate specific patterns described by the models of punctuated equilibrium and attention-issue cycles. 
The remainder of this paper is structured as follows. In the following section, the methodology applied for the analysis is presented, including selection of issues, sample, and data mining technique. In the next section the concepts of punctuated equilibria and attention cycles are explored further. The results are then presented considering general and regional trends followed by a discussion. We conclude with consideration of the main findings and directions for future work.

\section{METHODOLOGY}

The data was collected using a basic text mining technique (after Hearst, 1999; Manning and Schütze, 2002) for discovery of knowledge using textual databases (after Feldman and Dagan, 1995; Fayyad et al., 1996; Tan, 1999). Text mining refers to generating patterns or knowledge from unstructured or semi-structured text (Tan, 1999; Feldman and Sanger, 2007), by searching for specific words contained in a sample of documents (after Lent et al., 1997). Analysis of environmental issues through textual analysis of newspaper articles has been used in a number of studies (Mazur and Lee, 1993; McComas and Shanahan, 1999), though none of the previous studies use such extensive sample as this study. This text mining technique allows us to consider a similar longitudinal sample across a diverse geographical range. Using printed news media facilitates the comparative dimension of our study. Whilst there would be much value in also considering online and other visual forms of communication, these would be subject to much higher levels of interpretation bias and are extremely problematic data sources to capture in a manner that allows comparison across cultures, continents, and time. The vast majority of previous studies have focused on print media and these have established a correlation between the public agenda-setting dimension and levels of print media coverage in broadsheets (Sparks, 1987; McCombs, 2004; Carvalho and Burgess, 2005).

Our sample consists of 112 worldwide newspapers from 39 countries in seven languages (English, Spanish, Italian, German, Dutch, French, and Portuguese). The newspapers selected were all 'broadsheets', as these can be expected to provide the highest amount of coverage on political issues and to have the highest agenda-setting impact for policy makers and the general public (Carvalho and Burgess, 2005). We were also restricted by the availability though online databases such as LexisNexis. Selection criteria also included circulation, area of circulation (primarily national), ideally in private ownership and where some degree of freedom of the press exists. McComas and Shanahan (1999) recommend that searches of newspaper databases should consider not only the title of the article but the body of the text. We adopt this protocol within our study, searching the full text of the article. We selected one specific issue (climate change) and a conceptual idea (sustainability-sustainable development) for the data mining process and analysis in this paper.

Downs (1972) acknowledges that the issue-attention cycle model only holds for issues that carry certain characteristics: he suggests that the model applies to issues that adversely affect a minority of the population, have been created beyond the threshold of public attention, and are able to trigger dramatic peaks in public attention (Downs, 1972; Howlett, 1997). It can be assumed that both climate change and sustainable development meet these criteria.

Figure 1 describes the development of sustainability related issues in the worldwide sample of 112 newspapers from January 2005 to December 2008. It illustrates that over these three years coverage of climate change became a dominant theme in the news media, with an increase in coverage from around 10-20 articles per newspaper and month in the year 2005 up to an average of 60 articles per newspaper per month at the end of 2008. Likewise, Figure 2 displays the development of worldwide newspaper coverage on a number of corporate sustainability related concepts between 1990 and 2008. It shows that, unlike coverage on more specific corporate concepts such as business ethics or corporate social responsibility, sustainability-sustainable development is also an issue of growing 
dominance within the last five years. Therefore, these two items were selected for the data mining exercise. Figure 1 illustrates that there are a number of other issues that are worthy of further analysis, but these are outside the boundaries of this paper. For the purposes of this paper, we combined the sustainability and sustainable development terms in the data mining, and henceforth 'sustainability' refers to the joint sample of sustainability and sustainable development. Although sustainable development is a more restricted technical term than sustainability, they both refer to the same basic conceptual framework. In addition, whilst in English language newspapers sustainability has become the most widely used term in this context, French newspapers commonly refer to the same set of related issues as sustainable development (développement durable) rather than sustainability (durabilité).

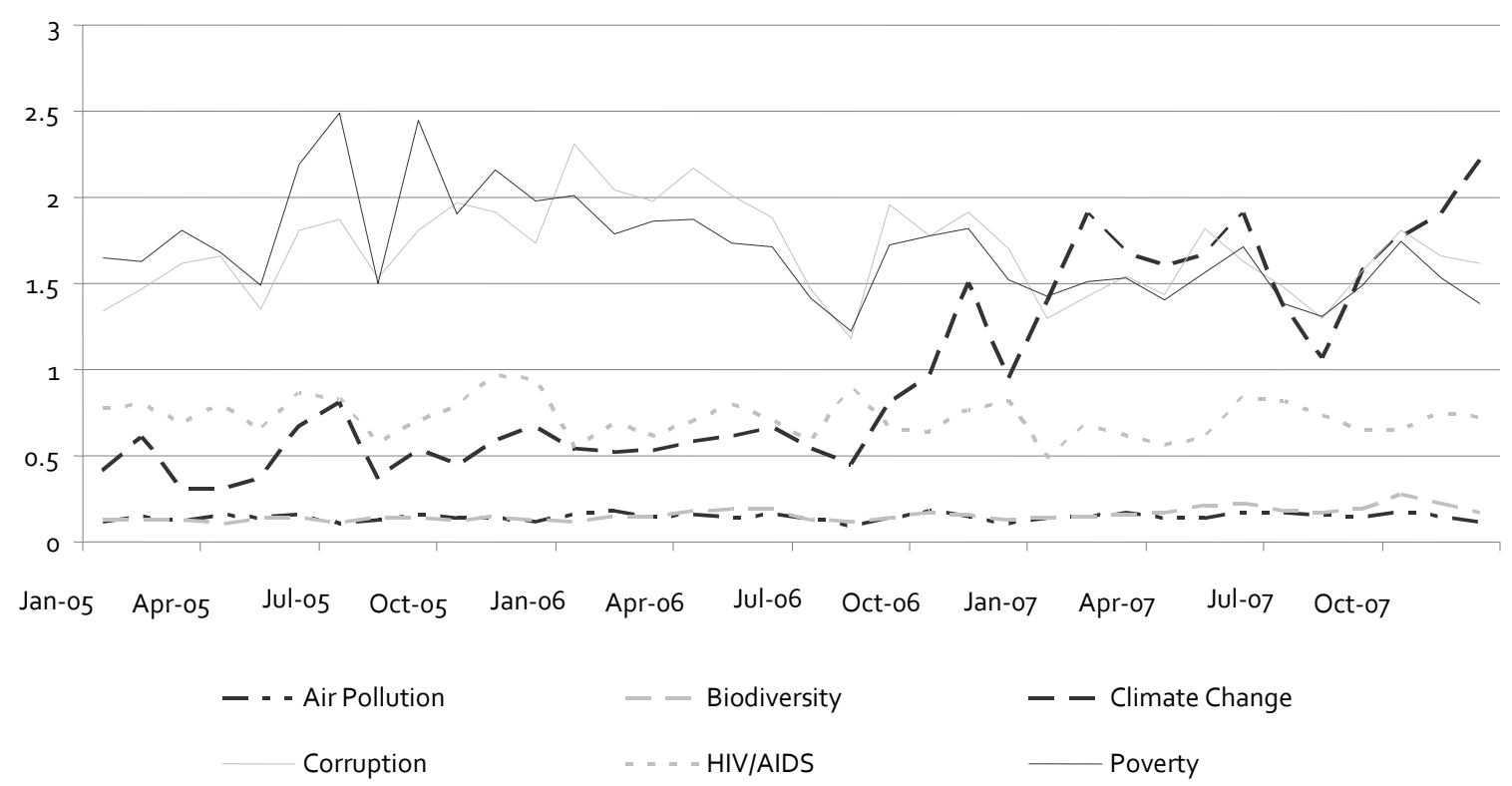

Figure 1. Overview of coverage of sustainability issues within worldwide sample of news media (hits per issue)

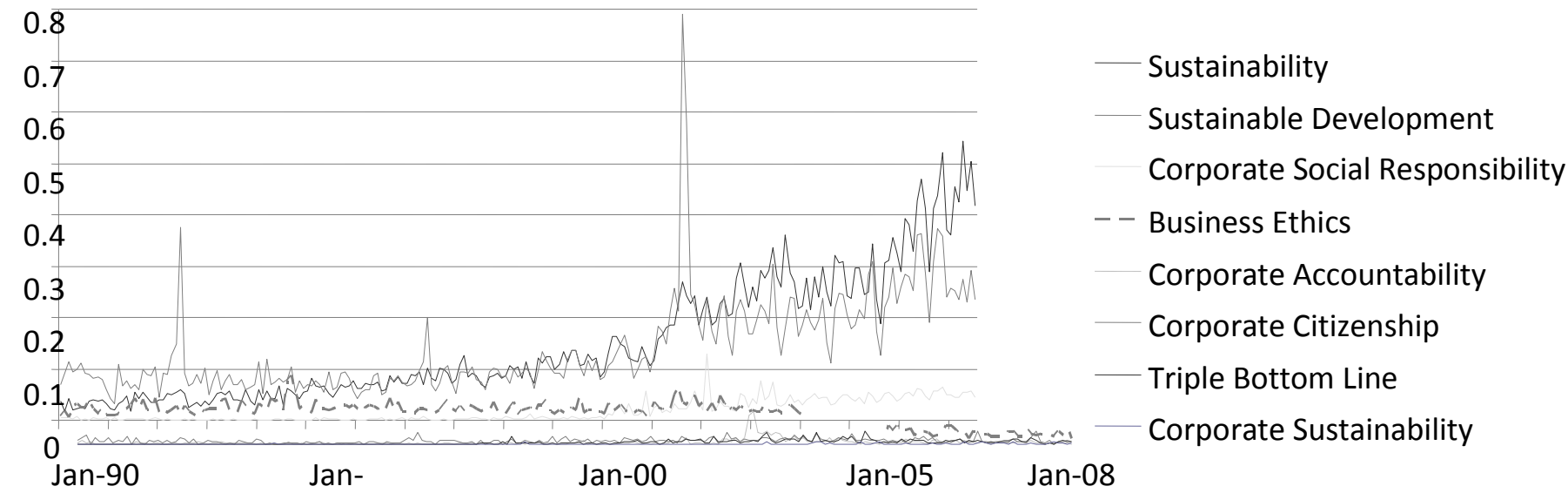

Figure 2. Overall coverage of various corporate sustainability-related concepts (hits per issue) 
In the first stage the results of the data mining process were converted into frequency tables and the monthly average number of hits (articles containing the search term) per newspaper issue calculated as the base unit of analysis. This allows for comparison of different newspapers, as it takes into account that some newspapers are released daily, whereas others are only released on weekdays. Therefore, a sample frequency of 0.1 for 'climate change' represented a probability of $10 \%$ for that month that any newspaper bought would have at least one article that mentioned this term within it. Hits per issue $=\quad \frac{\text { total number of monthly hits/number days in month }}{\text { (issues per week/7) }}$

The data was collected from a 19 year time period from 1990 to 2008. January 1990 was chosen as the start date to precede the fi rst major sustainability policy event (the Rio Summit of 1992). This period also coincides with the end of the second up wave of environmentalism, which began in 1988 , focusing on green consumer issues, and the start of the downturn of 1991, sparked by the Gulf War and recession (SustainAbility,2002). Some newspapers began publication later; for instance, South African newspapers were only included in the analysis as of July 2006 . However, we decided to include these newspapers from the date they became available in order to increase regional diversity of the sample. We also need to consider the influence of syndication of newspaper articles. However, we would argue that due to the sample size and regional diversity the impact of syndication remains limited. In order to avoid double counting, articles that appeared in regional editions were not included in the sample. We acknowledge that there is a trade-off between precision and spread of data collected, as newspapers enter the sample at different stages along the timeline. We believe that this trade-off is acceptable given the need to access such a wide geographical spread over such a long time period. Data was entered into Excel spreadsheets to develop the summary diagrams that illustrate the trends in coverage and assign trend lines. The data was also grouped into national sub-samples to allow further analysis within the statistical package SPSS.

\section{DESCRIBING THE DATA PATTERNS}

This section introduces the literature that describes the different models we are considering as explicators of the patterns we see within the data. This is not meant to be an exhaustive literature review and is designed to set the general context for each of the possible theoretical models.

\section{Issue-Attention Cycle}

Downs (1972) proposes that an issue-attention cycle influences public attitudes and behaviour with regard to key domestic issues and that consideration of this cycle provides insights into how effectively an issue can engage with the public and political process. A summary of the cycle is detailed in Table 2. A number of studies have considered the applicability of Downs' issue-attention cycle to environmental news media (Dunlap, 1995; McComas and Shanahan, 1999; Thøgersen, 2006).

Downs $(1972$, p. 46) suggested that 'the greater the apparent threat ... the more vividly this can be dramatized, the more public support environmental improvements will receive and the longer it will sustain public interest'. Anecdotal evidence of the rise and fall of public interest in sustainability issues is recounted by journalists (Smith, 2000), who note the difficulties that they face in maintaining sustained levels of interest in such issues given competing coverage of other topics (Harrabin, 2000; May and Pitts, 2000), even when events are dramatically visualized. May and Pitts (2000, p. 24) note that 'the media responds to breaking news, to new things, to change'. This makes maintaining levels of sustained interest on a topic such as sustainability a difficult challenge. 
When we consider the history of environmentalism it is clear that some issues rise to prominence around a specific event and then fade from public view, as illustrated by Farrow's consideration of the communication of climate change news. She cites the journalist Paul Brown's post-Rio comments 'my stories went from page 1 to page 3 to page 7 . . there was no new science ... then Mt Pinatubo exploded ... there was a worldwide recession' (Farrow, 2000, p. 194). She recalls that the focus then shifted to identifying how other stories had climate change connotations. Thus in her rendition of the prominence of climate change commentary over that time period a pattern emerges of an issue rising to prominence and then falling back, in many ways like Downs' cycle, then shifting focus subtly to reinvigorate the debate and restart the cycle. This suggests a cyclical process as described in Figure 3.

This apparent cycling around an issue-attention cycle owes much to the residual level of interest in Stage 5, as noted by Downs (1972). McComas and Shanahan (1999) also comment that, once an issue cycle ends, the printed news media is likely to use the narrative outcome of that cycle as a presumption upon which to build the next cycle; i.e., the roots for the next cycle lie with the previous one. However not all issues follow this pattern in her study - some issues appear resolved and are consigned to historical records (an example might be CFCs resolved by the Montreal Protocol). Perhaps another reason is that other issues have to compete for coverage against other concerns that may be more topical and crowd out the newspaper space available. This pattern might be seen in issues such as HIV Aids and poverty, which show decline or stagnation in coverage as climate change and sustainability concerns rise on the agenda (as illustrated by Figure 1). This tradeoff between competing issues is part of the shift between different stages of the issue-attention cycle. Further analysis of the content of coverage would allow each communiqué to be placed into one of the five stages of the issue-attention cycle (after McComas and Shanahan, 1999).

Table 2. The issue attention cycle adapted from IISD (2007)

\begin{tabular}{|l|l|}
\hline $\begin{array}{l}\text { Stage 1: } \\
\text { Pre-problem stage }\end{array}$ & Undesirable social condition without much public attention \\
\hline $\begin{array}{l}\text { Stage 2: } \\
\text { Alarmed discovery and euphoric } \\
\text { enthusiasm }\end{array}$ & $\begin{array}{l}\text { Result of dramatic events the public becomes aware and alarmed. Some react with } \\
\text { enthusiasm that society has ability to solve issue in short time period - others are more } \\
\text { pessimistic }\end{array}$ \\
\hline $\begin{array}{l}\text { Stage 3: } \\
\text { Realizing the cost }\end{array}$ & $\begin{array}{l}\text { gradual realization of the cost of 'solving ' problem that requires money and sacrifice } \\
\text { (equitably from all segments of society) }\end{array}$ \\
\hline $\begin{array}{l}\text { Stage 4: } \\
\text { gradual decline of intense } \\
\text { interest }\end{array}$ & $\begin{array}{l}\text { Widespread acceptance of difficulty and cost of finding solution leads to discouragement, } \\
\text { suppression of thought or boredom with issue public interest wanes and other issues enter } \\
\text { stage 2 diverting interest }\end{array}$ \\
\hline $\begin{array}{l}\text { Stage 5: } \\
\text { post-problem }\end{array}$ & $\begin{array}{l}\text { Issue moves into limbo - lesser or spasmodic interest but leaves the infrastructural/policy } \\
\text { initiatives resulting from progression through stages 1-4. Residual levels higher than stage }\end{array}$ \\
\hline
\end{tabular}

\section{Punctuated Equilibrium}

Application of evolutionary theory models, such as punctuated equilibrium, to the study of change in organizations, technology, and policy is an approach that has been used by a number of authors (Romanelli and Tushman, 1994; Katsanis, 1995; Lichtenstein, 1995). From a biological perspective, punctuated equilibrium suggests that evolutionary shifts occur in infrequent transformative punctuations to a new 'species' (Eldredge and Gould, 1972). Within management research the suggestion is that systems remain relatively stable for long periods of time but are punctuated by short periods of rapid change (Schot, 2007), in the form of punctuated equilibrium. Romanelli and Tushman (1994, p.1141) provide one of the few empirical tests of this concept of organizations 
'evolving through long period of stability (equilibrium periods) in their basic patterns of activity that are punctuated by relatively short bursts of fundamental change (revolutionary periods)'. These basic activity patterns are then disrupted and form the basis for the new equilibrium level. The concept of punctuated equilibrium has been applied to the evolution of environmental policy (Romanelli and Tushman, 1994; Howlett, 1997; Repetto, 2008) and to other national policy concerns (Turnock, 2001; Givel, 2006).

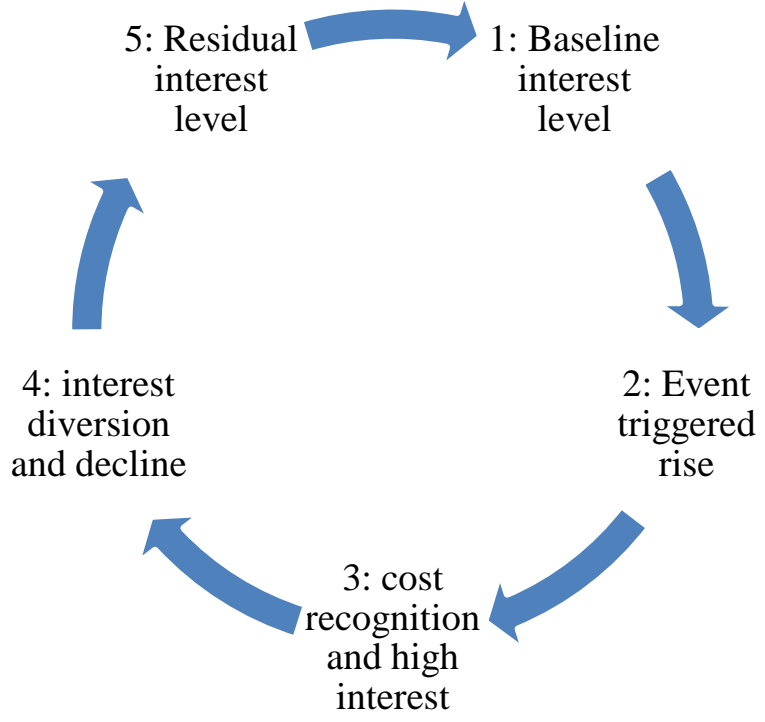

Figure 3. The cyclical issue attention cycle process (after Downs, 1972)

Most explorations of punctuated equilibrium commonly associate some form of event, an exogenous shock, with the resultant discontinuous change. In the biological sense this would commonly be associated with some form of catastrophe, which promotes natural selection of certain individuals. When punctuated change occurs within policy-making systems, these permanently alter prevailing power arrangements in dominant policy monopolies (Baumgartner and Jones, 1991, 1993; Howlett, 1997; True, 2002). Within organizational research such shock events may be figuratively be on the scale of a natural disaster such as a meteor strike. The disaster at Bhopal altered the way the chemical industry considered environmental risk and led to developments in environmental management systems. Policy events such as the Rio Summit might bring new concepts, such as sustainable development, into the political and legislative arena and could be considered as 'trigger events', theoretically moving sustainability concepts and practice from a static equilibrium, through a punctuation, to a new 'normal' (represented in Figure 4).

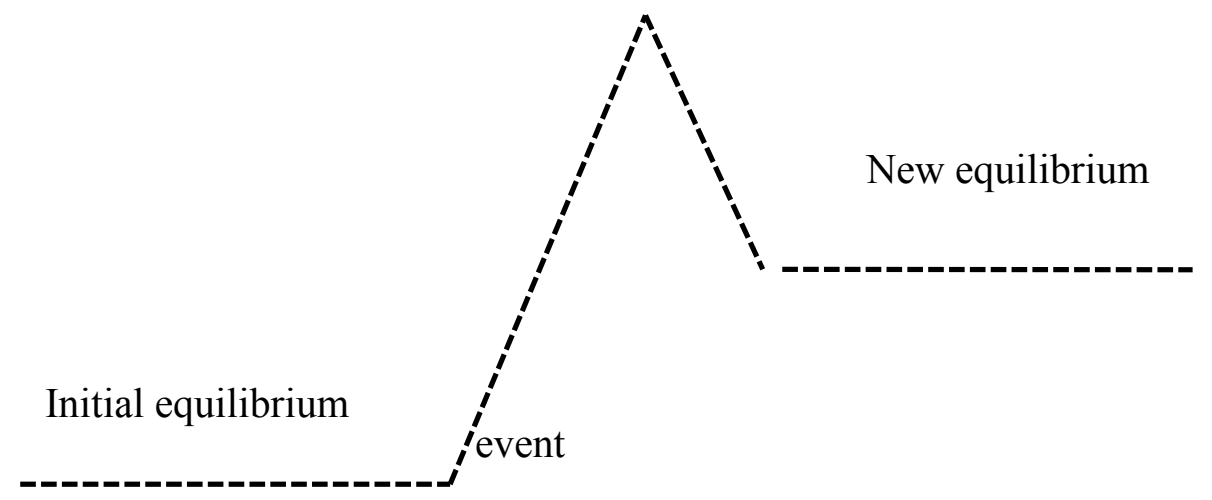

Figure 4. Representation of punctuated equilibrium in organisational and environmental policy research 
This concept also has parallels with Gladwin's concept of the idea of 'tipping points' where concepts enter public consciousness (Gladwin, 2000). Punctuated equilibrium is described by organizational researchers, but there is little theoretical development for how and why this process may occur in social systems (Baumgartner and Jones, 1993; Givel, 2006). The role of the media may play an important part in this process and we therefore consider this within our study.

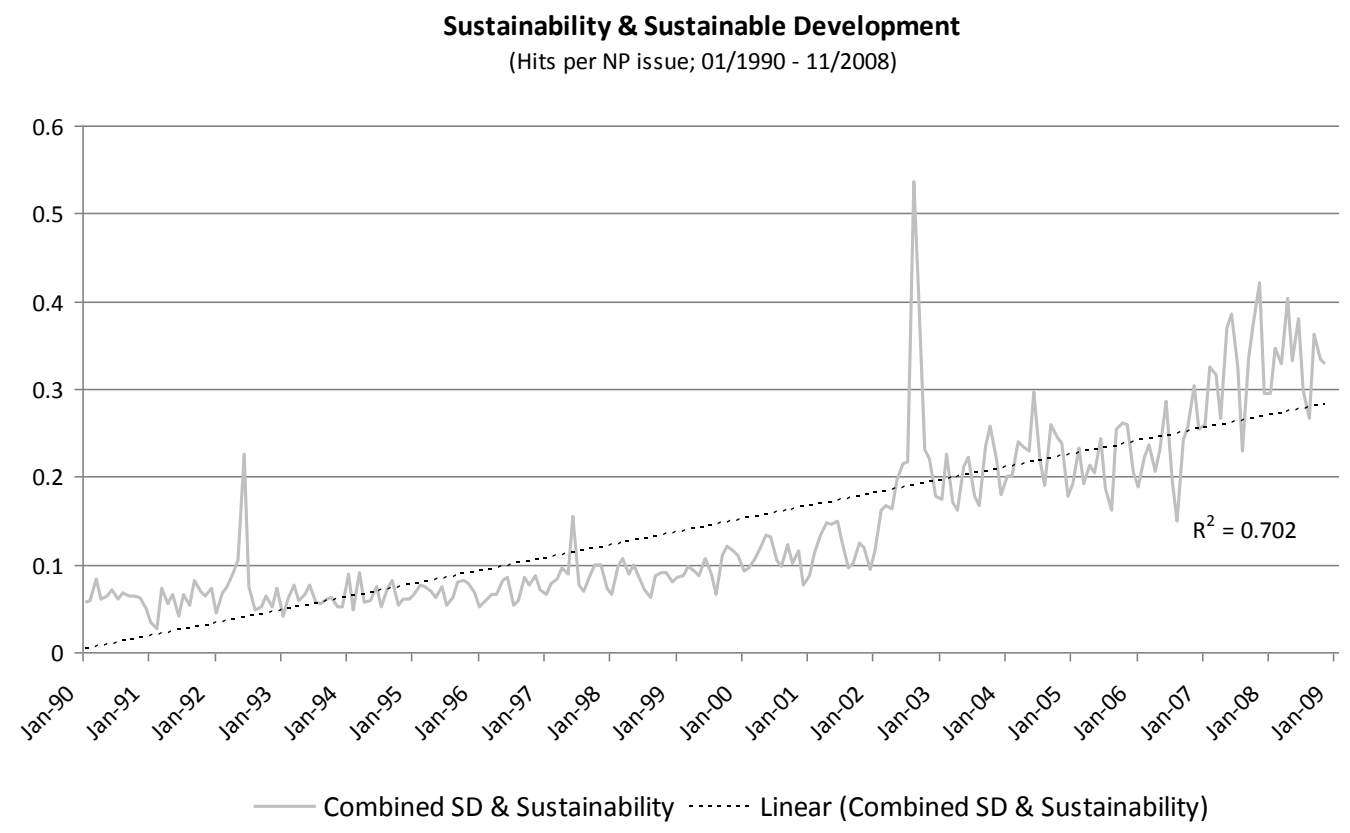

Figure 5. Coverage of 'sustainability or sustainable development' in worldwide sample of newspapers - hits per issue

\section{FINDINGS}

\section{General Trends in Coverage}

Figure 5 illustrates the newspaper coverage of sustainability and sustainable development across the worldwide sample. The regression equation has an $R 2$ value of 0.70 and clearly shows that there is an upward trend over the last 19 years in coverage of sustainability (and sustainable development). The three major peaks are related to the policy events of Rio (1992), Kyoto (1997), and Johannesburg (2002). From 2002 onwards sustained overage is evident, with none of the downward waves reaching down to the pre-Johannesburg level of 0.1 .

Overall levels of coverage of climate change remain more limited than coverage of sustainability, but both issues of climate change and sustainability have higher totals than most other environmental and social issues (when compared with Figures 1 and 2). Coverage of climate change demonstrates a large upsurge from early 2007 onwards (Figure 6).

The sample we examine consists of 39 countries, 7 languages, and 112 newspapers over 19 years. Therefore we can cluster the findings into regional representation. Much of the previous work that examines newspaper coverage of environmental issues adopts a restricted sample, including that of Wollin (1999). We have analysed the coverage of worldwide samples as the main basis for this paper, as we consider that these capture the greatest diversity and represent the 'global' picture. However, examination of some of the differences in regional coverage is an important consideration, and we briefly consider this in the next section. 


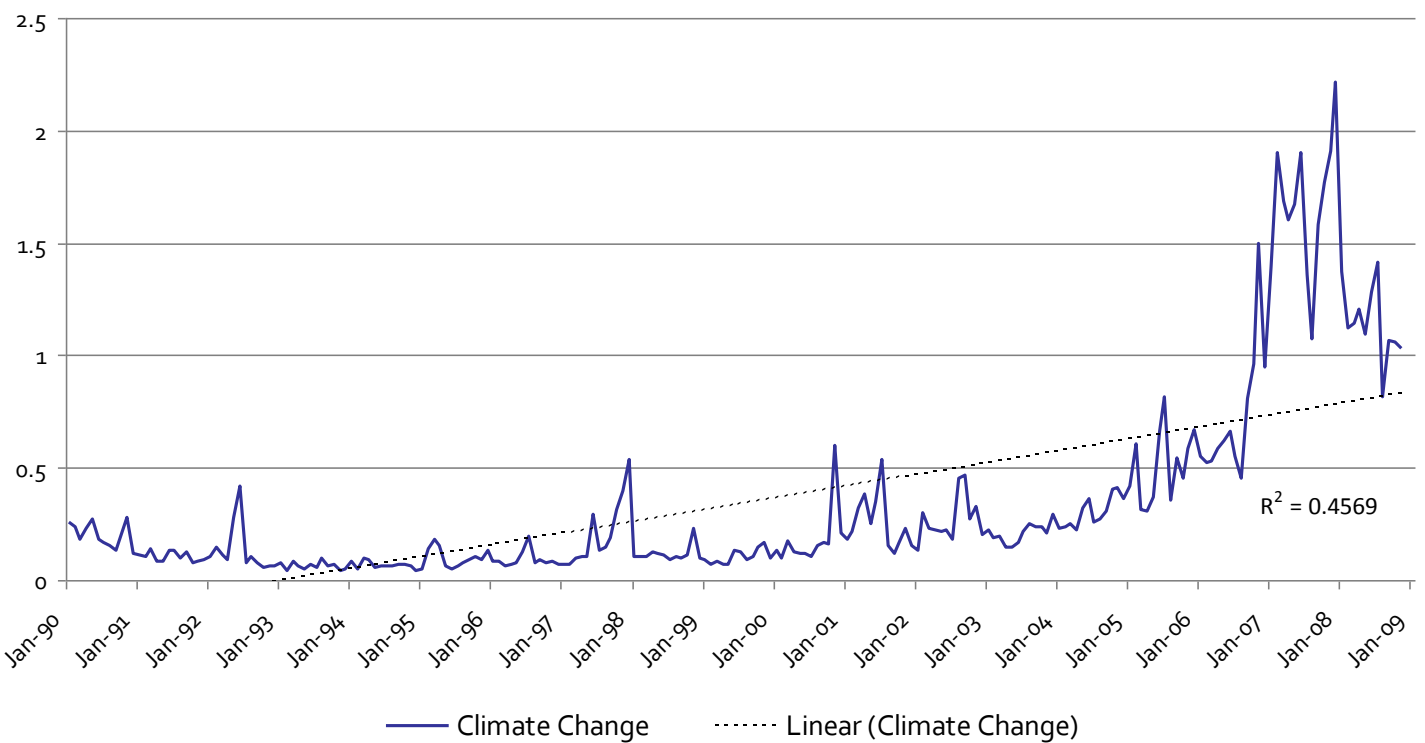

Figure 6. Coverage of climate change in worldwide sample of newspapers

\section{Trends in Regional Coverage}

In this section we consider the trends emerging in coverage in the regional sub-samples and the total worldwide sample. First we consider a general overview of the data by examining the descriptive statistics presented in Table 3. It is clear that differences do emerge between coverage of the total population and the regional sub-samples. For instance, the data for Canada and Australia has a similar mean, but coverage is significantly skewed within the Australian sample, with a maximum of 11.35, compared with 4.47 in the Canadian dataset. In the second stage of the analysis the data was normalized by dividing the average for the total population by the value for the regional sample, to illustrate the how the regional sub-samples compare with the general trend displayed as a percentage. Thus if coverage in the worldwide sample was identical to that in the regional sample in any given month the resultant value would be $100 \%$, and all regional values below the $100 \%$ grid line are below the worldwide average.

Table 3. Descriptive information on worldwide and regional data

\begin{tabular}{|l|r|r|r|r|r|r|}
\hline & No. months & Mean & Max & Std. Deviation & \multicolumn{1}{l|}{ Skew } & Std. Error \\
\hline Worldwide sample Sustainability & 226 & 0.14 & 0.54 & 0.10 & 1.20 & 0.16 \\
\hline Worldwide sample climate change & 226 & 0.34 & 2.22 & 0.43 & 2.31 & 0.16 \\
\hline Australia sustainability & 226 & 0.21 & 0.81 & 0.18 & 1.27 & 0.16 \\
\hline Canada sustainability & 226 & 0.13 & 0.51 & 0.11 & 1.40 & 0.16 \\
\hline USA sustainability & 226 & 0.10 & 0.59 & 0.07 & 2.77 & 0.16 \\
\hline UK sustainability & 226 & 0.18 & 0.80 & 0.12 & 1.42 & 0.16 \\
\hline South Africa sustainability & 143 & 0.39 & 2.36 & 0.40 & 2.04 & 0.20 \\
\hline Southeast Asia sustainability & 199 & 0.12 & 0.39 & 0.07 & 0.95 & 0.17 \\
\hline Australia climate change & 227 & 0.77 & 11.35 & 1.54 & 3.40 & 0.16 \\
\hline Canada climate change & 227 & 0.61 & 4.47 & 0.82 & 2.15 & 0.16 \\
\hline USA climate change & 227 & 0.25 & 1.20 & 0.26 & 2.00 & 0.16 \\
\hline UK climate change & 227 & 0.84 & 4.43 & 1.02 & 1.77 & 0.16 \\
\hline South Africa climate change & 144 & 0.17 & 0.98 & 0.23 & 1.64 & 0.20 \\
\hline Southeast Asia climate change & 200 & 0.12 & 1.26 & 0.20 & 2.92 & 0.17 \\
\hline
\end{tabular}




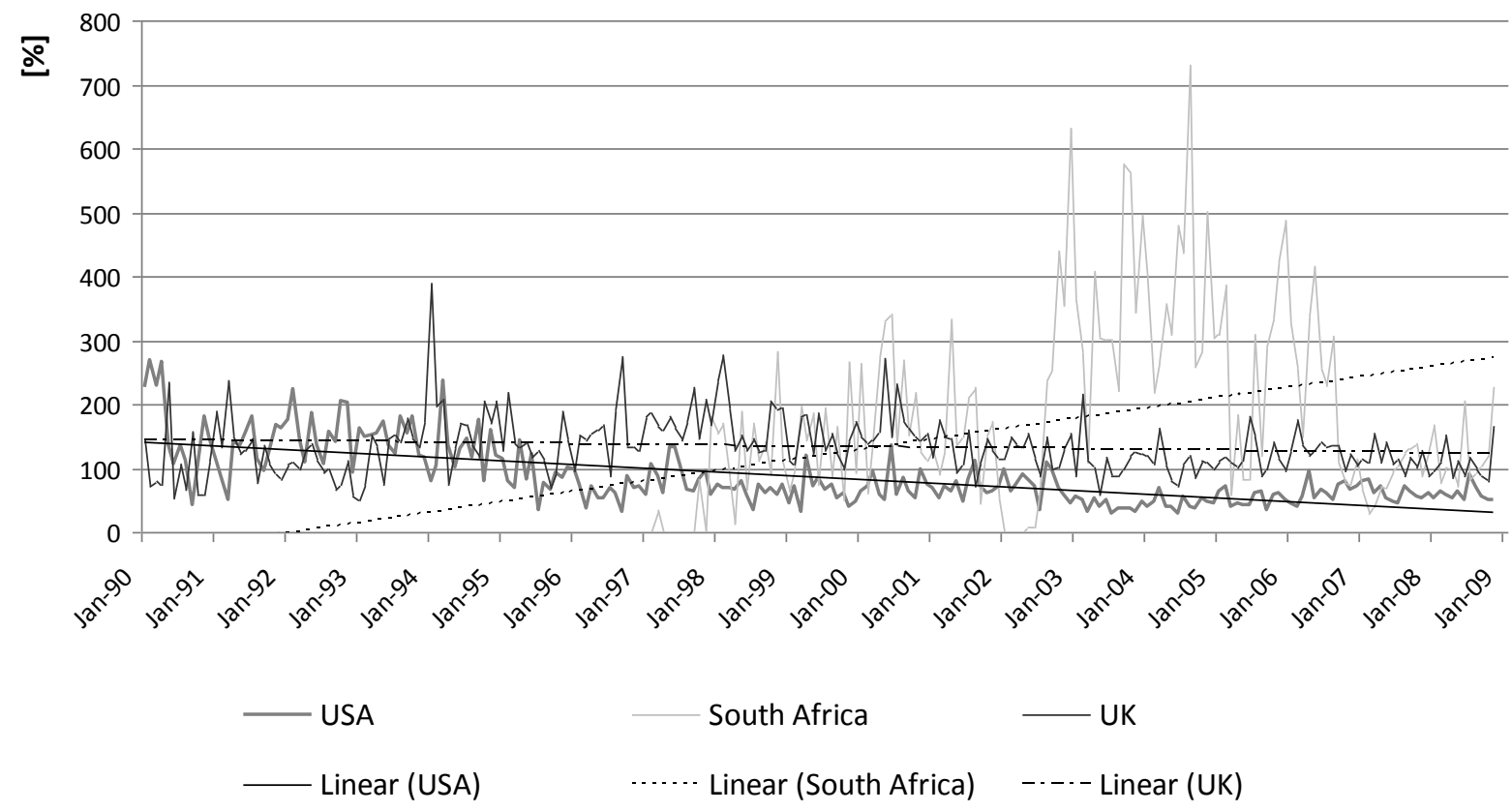

Figure 7. Comparison of sustainability coverage within USA, UK and South African sample compared against the worldwide average (100\%)

\section{Climate Change - Comparison of Regional Trends}

(Hits per NP issue; 1990-02/2008; 100\% = worldwide trend)

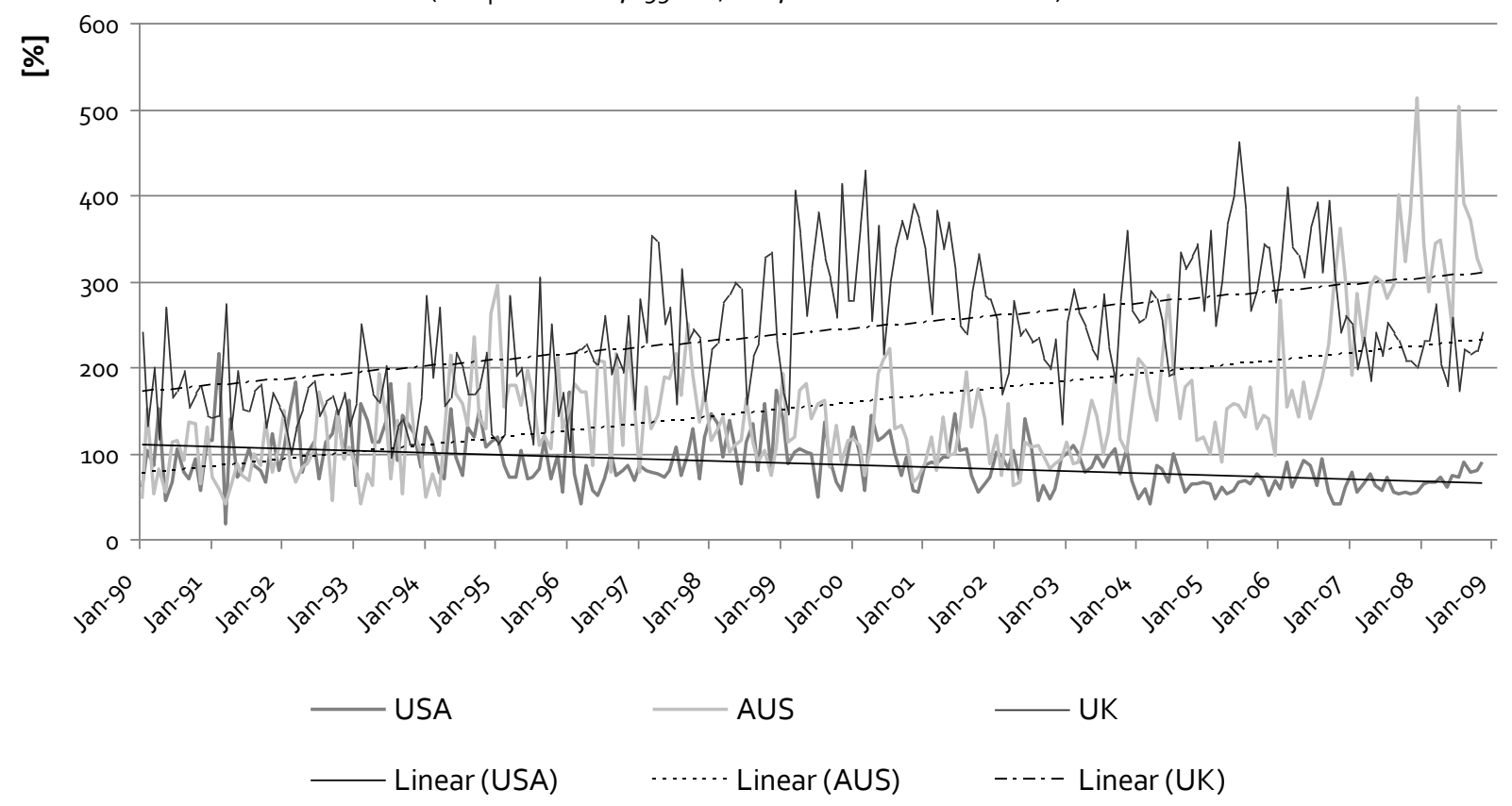

Figure 8. Comparison of climate change coverage within USA, UK and Australian sample compared against the worldwide average (100\%)

A selection of these regional trends is presented in Figures 7 and 8. This is not an exhaustive analysis of this data, as this merits a fuller examination outside the bounds of this paper. However, a number of important conclusions can be inferred. 
- There is a higher impact of some events regionally; in particular, the World Summit in Johannesburg seems to have triggered a 4-5 year long phase of extremely high coverage of sustainability in South Africa.

- In some countries the increase in coverage started earlier: for example, within the UK climate change peaks begin to rise from 2000 onwards. In contrast, all 14 Australian and US newspapers remain at relatively low coverage levels over the same sampled period, until coverage also starts to show significantly higher peak levels in mid-2005 (Australia) or even the end of 2006 (USA).

- There is an overall downward trend within the US newspapers compared with the global average, more or less continuously declining in cases of both sustainability and climate change.

- In Australia the coverage of climate change in the last two years has been up to five times higher than the global average.

\section{Testing the Differences Between Time Periods}

When considering the data we are looking for evidence of two possible patterns: an issueattention cycle and/or punctuated equilibrium. If some form of punctuated equilibrium has taken place then a discontinuous break in the data will be evident. By calculating the means for each yearly block of data across the whole sample we can establish 19 time points and smooth out the trend lines. We decided to adopt this approach rather than using the monthly data points presented earlier. The resultant pattern for the sustainability data is illustrated in Figure 9.

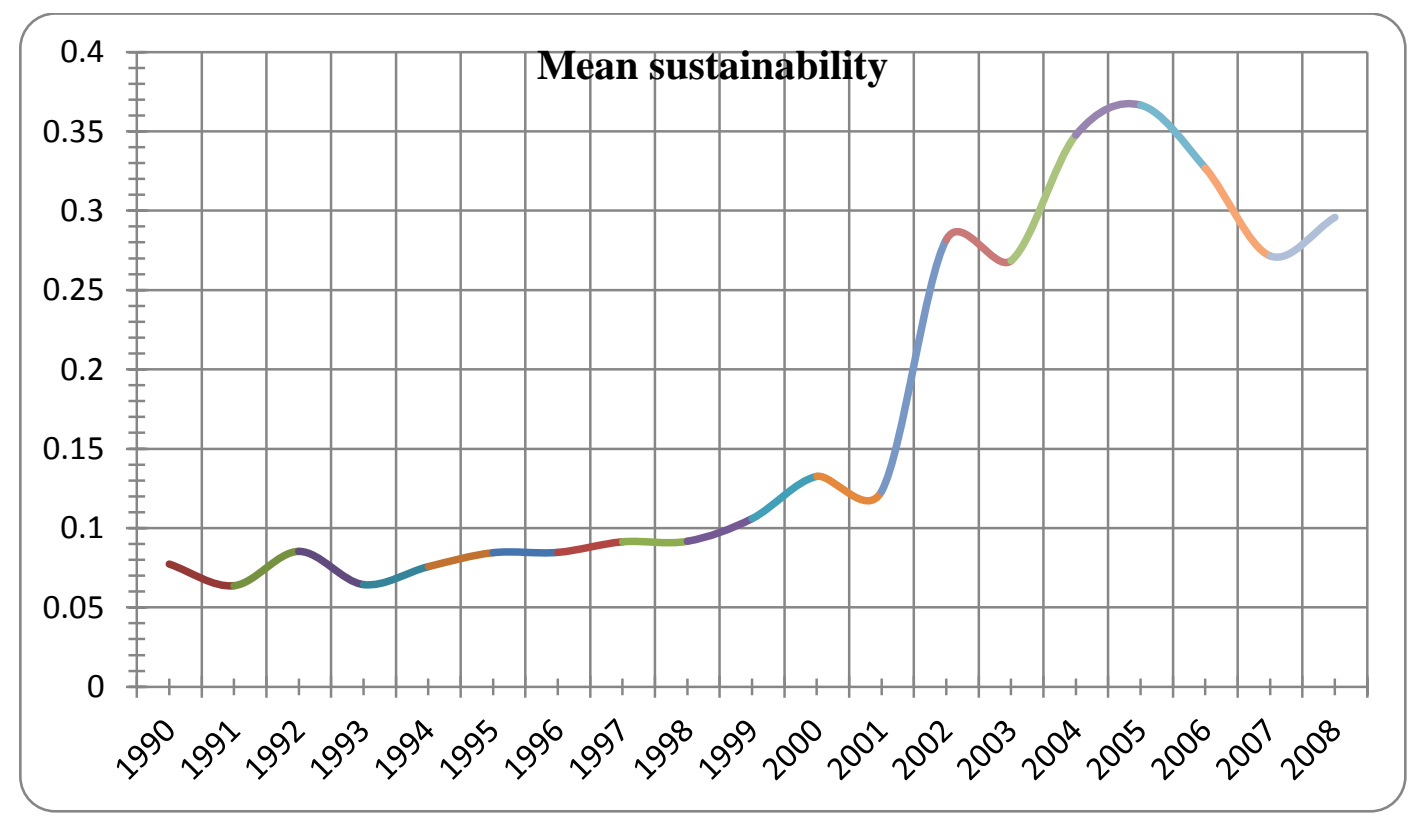

Figure 9. Patterns in sustainability coverage worldwide- mean per month(1990-2008)

There are two possible patterns in evidence in Figure 9. The first is that we are seeing the early stages of the issue-attention cycle, namely the upward surge demonstrated in Stages 2 and 3 . The second possibility is that some aspects of punctuated change may be occurring, with an equilibrium demonstrated in from the period 1990-2001 and a discontinuous change in 2002, leading to higher level of awareness via coverage from this point on. However, there is a minor peak in 1992 so we can also test for the effect of this. 
Therefore, the sample can be split into four with data from 1990 to 1991 (just prior to the Rio Summit) classified as Time 1, 1993-1999 as Time 2, 2000-2002 (Johannesburg took place in 2002) as Time 3 and 2003-2008 as Time 4. Since the data is not normally distributed a non-parametric test of means is used (Kruskal-Wallis with post hoc Mann-Whitney tests). A Bonferroni adjustment is used to control for Type 1 errors, with alpha at $p<0.05$ adjusted to 0.0125 , and $p<0.01$ adjusted to 0.001 25 (after Tabachnick and Fidell, 2007). Effect size was based on Cohen (1988) by calculating $r=z n$, where $n=$ total number of cases. An effect size of 0.1 is considered small, 0.3 medium, and 0.5 large.

All the groups in the sustainability data demonstrated significant differences at $p<0.05$ (adjusted to 0.0125). The mean ranks indicate the upward trend within the data (Table 4). The post hoc tests show significant differences between all groups, though the effect between Time 1 (1990-1992) and Time 2 (1993-1999) is less than the others. The Mann-Whitney $U$ test was significant at $p<0.05$, but not at $p<0.01$ (adjusted to 0.0025 ). This suggests that the impact of Rio was less than that Johannesburg in terms of coverage. Therefore, whilst Rio appears to have set the stage, it is the 2002 summit that appears to demonstrate a sharp punctuation change in coverage.

Table 4. Results of the Kruskal Wallis Test for difference between groups- sustainability coverage

\begin{tabular}{|c|c|c|c|c|c|c|c|}
\hline Kruskal -Wallis & $\mathbf{N}$ & $\begin{array}{c}\text { Mean } \\
\text { Rank }\end{array}$ & $\begin{array}{l}\text { Post-hoc Mann Whitney } \\
\text { U Test }\end{array}$ & $\mathbf{n}$ & $\mathbf{z}$ & $\mathbf{p}$ & $\begin{array}{l}\text { effect } \\
\text { size }\end{array}$ \\
\hline 1990- 1992 & 23 & 38.37 & Time 1 vs Time 2 & 119 & -3.362 & 0.01 & -0.3 \\
\hline 1993-1999 & 96 & 67.78 & Time 2 vs Time 3 & 120 & -6.193 & 0.000 & -0.59 \\
\hline $2000-2002$ & 24 & 123.29 & Time 3 vs Time 4 & 107 & -7.342 & 0.000 & -0.71 \\
\hline $2003-2005$ & 83 & 184.37 & & & & & \\
\hline
\end{tabular}

When examining the trends illustrated in Figure 9, there appears to be a lessening of coverage from the peak in 2005. This suggests that perhaps we can see a dual effect of both punctuated change and issue-attention cycles operating in tandem. Further exploration of this data could also consider each regional sample and compare them to see whether the shifts appear simultaneously.

The drop in coverage on sustainability may be linked to an increased focus on climate change (which peaked in 2006-2007), and there are some suggestions that economic priorities towards the end of 2008 may have caused a shift away from environmental issues, though this is yet to be fully substantiated. This study should be replicated at periodic intervals to continue to track the coverage and the evolving patterns within it. Later studies can also widen the focus to other issues to see whether we are seeing a widening shift in priorities.

There were extreme levels of coverage on sustainability in South Africa between 2002 and 2007 triggered by the Johannesburg summit (up to eight times higher than average, although the average itself increases over time), as can be seen in Figure 7. Using the worldwide sample allows these extremes in one region to be smoothed out to look at global trends, and provides larger sample size for statistical tests. However, it is clear that further exploration of this data should consider each regional sample and compare the differences between them to see whether the shifts appear simultaneously.

We now turn our attention to the worldwide climate change dataset, in the same manner as the example above. The pattern demonstrated here is subtly different from the sustainability one illustrated in Figure 9, with apparent peaks in 1992, 1997, 2002, and 2007. The first three appear to follow the global policy developments at Rio, Kyoto, and Johannesburg. The 2007 peak is slightly different and occurs at the same time as coverage of Al Gore's An Inconvenient Truth reached its peak and with Gore and the IPCC awarded the Nobel Peace Prize in October 2007. 


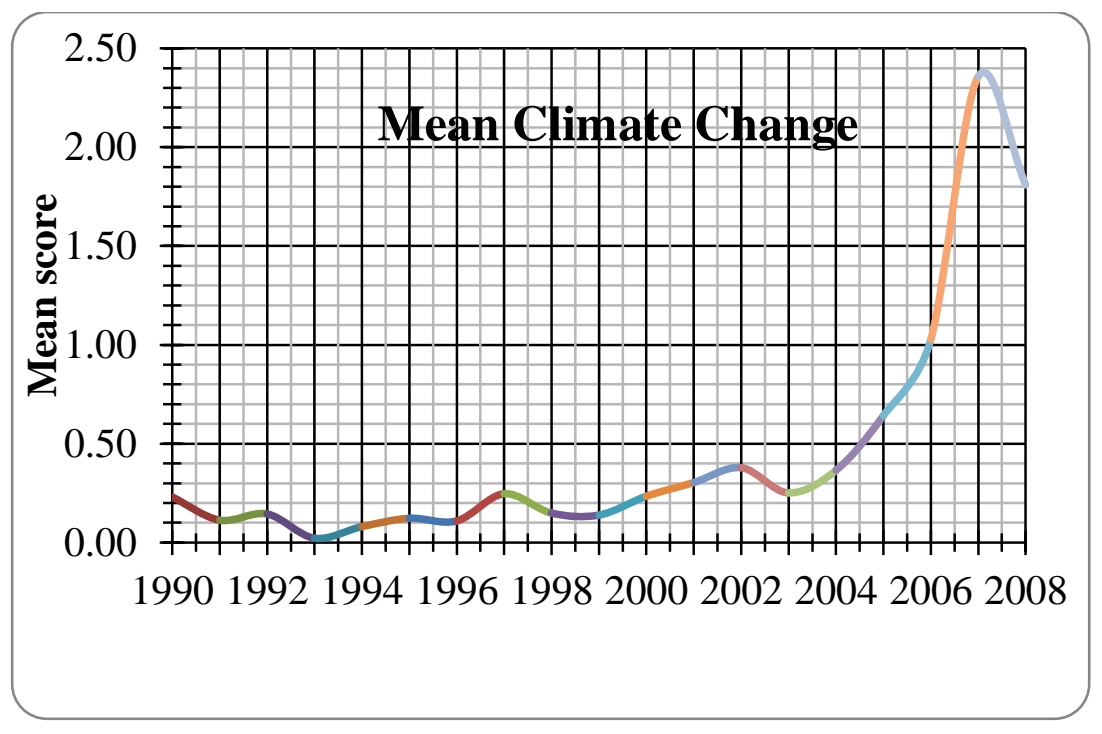

Figure 10. Patterns in climate change coverage worldwide mean per month

The pattern demonstrated in Figure 10 appears to demonstrate a ripple effect, much like a slowly building wave. This might represent a series of linked issue-attention cycles, where, similar to that described by McComas and Shanahan (1999), the antecedent residual effects of the previous issue cycle form the starting point of the next. Examination of the trends suggests that we can test for discontinuous breaks at 1990-1992 (Time 1), 1993-1997 (Time 2), 1998-2002 (Time 3), and 20032008 (Time 4), as illustrated in Table 5.

Table 5. Results of the Kruskal Wallis Test for difference between groups-Climate change

\begin{tabular}{|c|c|c|c|c|c|c|c|}
\hline & $\mathbf{N}$ & Mean Rank & $\begin{array}{r}\text { Post-hoc Mann Whitney } \\
\text { U }\end{array}$ & $\mathbf{n}$ & $\mathbf{Z}$ & $\mathbf{p}$ & $\begin{array}{r}\text { effect } \\
\text { size }\end{array}$ \\
\hline 1990-1992 & 35 & 87.54286 & Time 1 vs Time 2 & 95 & -3.657 & 0.0003 & -0.37 \\
\hline 1993-1997 & 60 & 52.73333 & Time 2 vs Time 3 & 120 & -6.05693 & 0.0000 & -0.55 \\
\hline $1998-2002$ & 60 & 107.5833 & Time 3 vs Time 4 & 131 & -8.15349 & 0.0000 & -0.71 \\
\hline $2003-2008$ & 71 & 182.6479 & & & & & \\
\hline
\end{tabular}

The findings from the climate change pattern suggest that there are statistically significant differences between all the time periods at $p<0.01$ (using an adjusted Bonferroni adjustment of 0.0125), though the trend line from 1990 to 2002 meanders in the $0-0.5$ band. It is post-2002 that the sharp increase occurs, much like the shift from Stage 2 to Stage 3 in the issue-attention cycle. When we compare climate change and sustainability, the sustainability data is higher 2001-2005, whilst climate change data remains relatively low. The Kyoto coverage in 1997 impacts the climate change data more than the sustainability data, and it seems that the two issues are not discussed simultaneously: rather, as coverage on one increases, coverage on the other lessens, though only slightly.

\section{DISCUSSION}

We now explore our findings with specific reference to the two models of issue-attention cycles and punctuated equilibrium. There are clear differences between the two samples and the patterns emerging within these. We would argue that there are clear links to the major policy events of Rio and Johannesburg for both issues, but climate change is also clearly linked to Kyoto. 
In the climate change there is a clear delineation between the previous periods before 2003 and the increasing levels of coverage from this point on. The release of An Inconvenient Truth in 2006 may have played an important role in promoting this rise, as there is no doubt that being associated with the political figure of Al Gore it was more likely to attract the attention of the newspaper media. Within the climate change data there appears to be a significant general shift in the levels of coverage. However, it could not as yet be defined as a clearly punctuated change as the coverage has started to tail off. It may represent a series of issue-attention cycles, each increasing in magnitude and length much like waves against the seashore.

In the sustainability data there appears to be a series of jumps in coverage starting in 2000 up to 2005 that perhaps mimic some form of punctuated change. Though there has been some reduction since 2005, the lowest point remains above 0.25 , whereas the trend prior to 2000 was below 0.15 . There does appear to be some form of punctuated change over the period 2000-2002, followed by what seems to be the peak of an issue-attention cycle with baseline coverage decreasing in 2008 to the levels seen in 2002.

In both cases there appear to be decreased levels of coverage towards the end of the dataset in late 2008. This is perhaps not surprising given the global focus on the financial markets, the 'credit crunch' as it was termed in 2008, and more latterly considered as a recession. Recently news media in the UK have questioned which has greatest priority in time of economic turmoil: the environment or the economy. UK Prime Minister Gordon Brown considers the recent decision to approve the $f 9$ billion expansion at Heathrow Airport as necessary to economic prosperity and that the needs of the economy and the environment have to be balanced (BBC, 2009). In the USA President Obama talks of a green revolution, using the environment as an opportunity to stimulate the economy in the downturn. This potential trade-off amongst the pillars of sustainability, the economy, environment, and society, is a debate that will perhaps be played out around the world, and there are interesting possibilities to explore the trade-offs between these by examining the upcoming coverage over the next few years.

In this research, we have considered parallels between levels of newspaper coverage on sustainability and climate change and the concepts of punctuated equilibrium and Downs' issueattention cycle. Within this paper we consider the trends in coverage but we do not consider resultant policy shifts. Given the diverse geographies and cultures, it would be difficult to consider the minutiae of national policies, and this is not the focus on this research. However, it is a consideration for future research, narrowing to focus on how policy shifts may be related to coverage levels. Within Downs' model the likely implication would be that cycling through Stages 2 and 3 would lead to growing pressure on public policy related to growing levels of public attention. In the case of a punctuated equilibrium such discontinuous shifts infl uence policy structures and may lead to permanent redesign of ministries, passing of legislation, and a more formal 'institutionalization' of this issue into public affairs.

The trends described within this paper suggest that both issue-attention cycles and punctuated equilibrium shifts may occur together. It could be argued that within Downs' cycle a punctuated equilibrium is the trigger that moves an issue from Stage 2 to 3. Resultant shifts in policy structures allow the issue to be institutionalized and a formal response emerges from governments. At this point individuals may enter Stages 3 and 4 of the cycle, leading to disinterest. If the issue is not resolved then stakeholders such as activists and NGOs seek to reinvigorate the issue and lead it back into Stage 2.

Future research could seek to relate specific policy changes, such as a new environmental department or a new piece of legislation, to the period after the discontinuous shift in levels of 
coverage, by considering the relationship between national coverage and national policy changes. Quental et al. (2010) use a range of proxy measures to measure changes in global sustainable development policy activity and state that 'political efforts are indeed characterized by measurable ups and downs'. Future studies could correlate the patterns of global political activity they identify with the patterns emerging in our study of media coverage. They further note the clear peaks in political activity coinciding with the decennial Earth Summits, a pattern that also emerges within our study.

Another consideration is the temporal nature of the punctuated shift - whilst we see changes suggesting a new 'normal', if we track this coverage over a longer period (perhaps decades) will we see the levels of coverage tail off? This would be the case if resultant policy shifts ' $f i x$ ' the issue under debate. In biological evolution mutations lead to a permanent shift in a species; in the case of the application of this concept to social sciences, the policy shifts are institutionalized until the issue is resolved. The issue-attention cycle appears to play a key role in moving an issue towards a punctuated shift and this is perhaps how they should be considered - as symbiotic processes.

A number of directions for future research are articulated throughout the paper, including

- Consideration of regional differences, identifying whether there are parallels between the trigger events and the timing of the cycles of coverage,

- The effect of the economic downturn on coverage of social and environmental issues,

- Examination of other issues to see whether they demonstrate similar patterns to the data presented here,

- Closer examination of the content of the articles to assign each one to a stage of the issueattention cycle and relate this to patterns in coverage over time,

- The relationship between policy shifts and coverage, especially in comparison with the forthcoming findings of Quental et al. (2010), and

- Further exploration and replication of the study presented here to consider the applicability of the punctuated equilibrium and issue-attention cycle concepts to the awareness of sustainability.

\section{CONCLUSIONS}

This paper has presented an exploration of climate change and sustainability data to analyse the emerging trends in coverage as a surrogate measure of public attention and arguably awareness. Our sample of 112 worldwide newspapers is one of the largest datasets used in a study of this kind.

The analysis has shown that both issue-attention cycle and punctuated equilibrium models appear to have merit in the discussion of the trends emerging within the data. In particular, there appear to be links between the models, suggesting that shifting from one stage to another in the issueattention cycle may be linked to the timing of a punctuated shift. Future researchers should consider the hypothesis that it is 'levels of public discourse' of an issue that are reflected by the issueattention cycle and that resultant policy shifts are the result of a punctuation. The trigger that causes the punctuation is related to the stages of the issue-attention cycle and the subject of the coverage that causes the discourse.

The application of punctuated equilibrium and issue-attention cycles to the study of sustainability communication and awareness building is an important contribution towards understanding the role the media has in engaging the public with sustainability. The media also has a vital dual role in agenda setting and transmitting information. By exploring how the media responds to this through their coverage, we can perhaps see how to keep sustained attention on engaging the public, and 
promote increased levels of awareness and knowledge of environmental and social issues in our societies, in the hope that this may influence behaviour and move us towards sustainability.

\section{ACKNOWLEDGEMENTS}

The authors would like to acknowledge the financial support of the German Federal Ministry of Education and Research (Grant number 07IFS11), and the support of the Trends in Sustainability research group in particular Prof. Frank Figge.

\section{REFERENCES}

Baumgartner F, Jones B. 1991. Agenda dynamics and policy subsystems. The Journal of Politics 53(4): 1044-1074.

Baumgartner F, Jones B. 1993. Agendas and instability in American politics. University of Chicago Press: Chicago.

BBC. 2008. Go-ahead for new Heathrow runway http://news.bbc.co.uk/1/hi/uk_politics/ 7829676.stm

Cohen J. 1988. Statistical power analysis for the behavioral sciences. Lawrence Erlbaum Associates: Mahwah, NJ.

Downs A. 1972. Up and down with ecology the 'issue-attention cycle'. The Public Interest 28: 38-50.

Dunlap RE. 1995. Public opinion and environmental policy. In Environmental politics and policy: Theories and evidence, Lester JR (ed). Duke University Press: Durham, NC.

Eldredge N, Gould SJ.1972. Punctuated equilibria: an alternative to phyletic gradualism. In Schopf TJM (ed). Models in Paleobiology. San Francisco: Freeman Cooper: 82-115.

Farrow, C. 2000. Communicating about climate change an NGO view. In The daily globe environmental change, the public and the media, Smith J. (ed). Earthscan: London: 189-197.

Fayyad U, Piatetsky-Shapiro G, Smyth P. 1996. From data mining to knowledge discovery: An overview. In Advances in knowledge discovery and data mining, U Fayyad, G PiatetskyShapiro, Smyth P and Uthurusamy R. (ed), MIT Press: Cambridge, MA: 1-36.

Feldman R, Dagan I. 1995. Knowledge discovery in textual databases. Paper presented at First International Conference on Knowledge Discovery and Data Mining, Montreal, Canada.

Feldman R, Sanger J. 2007. The text mining handbook. Cambridge University Press: Cambridge, MA.

Givel M. 2006. Punctuated equilibrium in limbo: The tobacco lobby and US state policymaking from 1990 to 2003. Policy Studies Journal 34(3): 405-418.

Gladwell M. 2000. The Tipping Point: How Little Things Make a Big Difference. London: Little, Brown and Company.

Harrabin R. 2000. Reporting sustainable development: A broadcast journalist's view. In Smith J (ed), The daily globe environmental change, the public and the media: Earthscan, London: 49-63.

Hearst, MA. 1999. Untangling text data mining. Paper presented at 37th Annual Meeting of the Association for Computational Linguistics, University of Maryland, Maryland.

Hester J, Gonzenbach W. 1997. The environment: TV news, real world cues, and public opinion over time. Mass Communication Review 22(1/2): 5-20.

Howlett M.1997. Issue-Attention and Punctuated Equilibria Models Reconsidered: An Empirical Examination of the Dynamics of Agenda-Setting in Canada. Canadian Journal of Political Science 30(1): 3-29.

IISD. 2007. The sustainable development timeline online at http://www.iisd.org/pdf/2007/sd timeline 2007.pdf.

Katsanis LP. 1995. Punctuated equilibrium and the evolution of the product manager. Journal of Product and Brand Management 4(3): 49-60.

Lent B, Agrawal R, Srikant R. 1997. Discovering trends in text databases. Paper presented at 3rd International Conference on Knowledge Discovery, Newport Beach, California. 
Lewis TL. 2000. Media representations of "sustainable development": Sustaining the status quo? Science Communication 21: 244-273.

Lichtenstein BM. 1995. Evolution or transformation: a critique and alternative to punctuated equilibrium. Academy of Management Best Paper Proceedings: 291-295.

Manning, C. D., and Schütze, H. 2002. Foundations of statistical natural language processing. Cambridge, MA.: MIT Press.

May RM Sir, Pitts R. 2000. Communicating the science behind global environmental change issues. In The daily globe environmental change, the public and the media Smith J. (ed), Earthscan, London: 15-25.

Mazur A, Lee J. 1993. Sounding the global alarm: Environmental issues in the US national news. Social Studies of Science 23(4): 681-720.

McComas K, Shanahan J. 1999. Telling stories about global climate change: Measuring the impact of narratives on issue cycles. Communication Research 26(1): 30-57.

Norris P. 2001. Digital divide civic engagement, information poverty, and the internet worldwide. Cambridge University Press, Cambridge.

Repetto R. (ed). 2008. Punctuated equilibrium and the dynamics of US environmental policy. Yale University Press. New Haven, CT.

Romanelli E, Tushman ML. 1994. Organisational transformation as punctuated equilibrium: An empirical test. Academy of Management Journal 37(5): 1141-1161.

Schot J. 2007. Niches in evolutionary theories of technical change. Journal of Evolutionary Economics 17(5): 605-622.

Smith, J. (ed). 2000. The daily globe environmental change, the public and the media. Earthscan, London.

SustainAbility. 2002. Good news and bad: The media, corporate social responsibility and sustainable development. SustainAbility, Ketchum and United Nations Environment Program, London.

Szerszyski B, Urry J, Myers G. 2000. Mediating global citizenship. In The daily globe environmental change, the public and the media, Smith J. (ed) Earthscan, London: 97-114.

Tabachnick BC, Fidell LS. 2007. Using Multivariate Statistics. Pearson International Inc, Boston, MA.

Tan A H. 1999. Text mining: The state of the art and the challenges. Paper presented at PacificAsia Conference on Knowledge Discovery and Data Mining PAKDD'99 workshop on Knowledge Discovery from Advanced Databases.

Thøgersen J. 2006. Media attention and the market for green consumer products. Business Strategy and the Environment 15(3): 145-156.

Tilbury D. 1995. Environmental education for sustainability: Defining the new focus of environmental education in the 1990s. Environmental Education Research 1(2): 195-212.

True JL. 2002. Saying "yes,"'"no," and "load me up" to guns in America. The American Review of Public Administration 32: 216-241.

Trumbo C. 1996. Constructing climate change: Claims and frames in US news coverage of an environmental issue. Public Understanding of Science 5(3): 269-283.

Turnock D. 2001. Environmental problems and policies in east central europe: A changing agenda. GeoJournal 55(2-4).

Ungar S. 1992. The rise and (relative) decline of global warming as a social problem. The Sociological Quarterly 33: 483-501.

Wollin A. 1999. Punctuated equilibrium: Reconciling theory of revolutionary and incremental change. Systems Research and Behavioral Science 16(4): 359-367. 